\title{
TEORIA CRÍTICA E TRANSDISCIPLINARIDADE: UMA APOSTA NO PROJETO EMANCIPATÓRIO
}

\author{
CRITICAL THEORY AND TRANSDISCIPLINARITY: AN INVESTMENT IN THE EMANCIPATORY \\ PROJECT \\ TEORÍA CRÍTICA Y TRANSDISCIPLINARIEDAD: UNA APUESTA EN EL PROYECTO
EMANCIPATORIO
}

\author{
Jacqueline de Oliveira Moreira* \\ Ana Cláudia Castello Branco Rena* \\ Diego Fernando Bolanos ${ }^{* * *}$ \\ Lucas Caetano Pereira de Oliveira ${ }^{* * *}$
}

\begin{abstract}
RESUMO
Este texto busca abordar os fundamentos da transdisciplinaridade no contexto de uma pesquisa desenvolvida em um ambiente que reúne sociólogos e psicólogos para trabalhar a questão da criminalidade, que convoca a juventude pobre e, com muita frequência, negra. "O manifesto da transdisciplinaridade”, escrito por Nicolescu (1999), base desta discussão, propõe uma nova posição dos homens em relação aos outros homens e à natureza. Assim, buscamos localizar a vertente filosófica que possibilitou esse salto de uma ciência disciplinar descritiva para uma ciência implicada com a prática, ultrapassando as falsas dualidades e buscando produzir conhecimento a partir da lógica da complexidade.
\end{abstract}

Palavras-chave: Transdisciplinaridade. Pesquisa. Psicanálise. Sociologia.

\section{ABSTRACT}

This paper intends to discuss the fundaments of transdisciplinarity in the

\footnotetext{
"Doutora em Psicologia Clínica pela PUC São Paulo, mestra em Filosofia pela UFMG, professora na Pós-Graduação em Psicologia da PUC Minas, psicanalista, bolsista produtividade CNPq PQ2, membro do GT da ANPEPP "Psicanálise, Clínica e Política", membro da Comissão de Propostas Socioeducativas do Fórum Permanente do Sistema Socioeducativo de Belo Horizonte. Projeto Aprovado APQ-02862-17 - Edital Universal Fapemig.

*Doutoranda em Psicologia pela PUC Minas (Conceito CAPES 5), Bolsista CAPES I, mestre em Psicologia na linha de Intervenções Clínicas e Sociais e graduada em Psicologia, com especialização em Clínica Psicanalítica pela PUC Minas, integrante do grupo de Pesquisa "Curso de Vida e Trajetória Delinquencial: um estudo exploratório dos eventos e narrativas de jovens em situação de vulnerabilidade”, coordenado pelo professor Bráulio Figueiredo Alves da Silva e financiado pelo Instituto de Estudos Avançados Transdisciplinar (IEAT/UFMG) - Cooperação.

${ }^{* *}$ Residente pós-doutoral no Programa de Pós-graduação em Conhecimento e Inclusão Social da Faculdade de Educação (FaE), da UFMG, doutor em Educação pela FaE - UFMG com Bolsa CAPES, bolsista CAPES, psicólogo e profissional em Ciências do Esporte da Universidade del Valle (Colômbia), membro do Lepsi-MG, Redes Coletivo Amarraçóes e Infeies.

"**** Mestrando em Sociologia pela UFMG, bolsista CNPq, graduado em Ciências Sociais pela UFMG, Integrante do grupo de Pesquisa "Curso de Vida e Trajetória Delinquencial: um estudo exploratório dos eventos e narrativas de jovens em situação de vulnerabilidade”, coordenado pelo professor Bráulio Figueiredo Alves da Silva e financiado pelo Instituto de Estudos Avançados Transdisciplinar (IEAT/UFMG) - Cooperação.
} 
context of a research project, which gathers sociologists and psychologists to work on the issue of criminality, which convenes the low-income and often black - Brazilian youth. Basarab Nicolescu's "Manifesto of Transdisiciplinarity" (1999), in which this discussion is based, proposes that human beings should change their position towards other human beings and towards nature. Thus, we make an effort to spot the philosophical thought, which made possible the leap from a descriptive, disciplinary science into a form of science that is more connected with practice, that is able to overcome false dualities and which seeks to produce knowledge based on the logic of complexity.

Keywords: Transdisciplinarity. Research. Psychoanalysis. Sociology.

\title{
RESUMEN
}

El presente texto busca abordar los fundamentos de la transdisciplinariedad en el contexto de una pesquisa desarrollada en un ambiente que reúne sociólogos y psicólogos para trabajar la cuestión de la criminalidad, que convoca la juventud pobre y, con mucha frecuencia, negra. "El Manifiesto de la Transdisciplinariedad", escrito por Nicolescu (1999), base de esta discusión, propone una nueva posición de los hombres en relación a los otros hombres y a la naturaleza. Así, buscamos localizar la vertiente filosófica que posibilitó este salto de una ciencia disciplinaria descriptiva para una ciencia implicada en la práctica, sobrepasando las falsas dualidades y buscando producir conocimiento a partir de la lógica de la complejidad.

Palabras-clave: Transdisciplinariedad. Pesquisa. Psicoanálisis. Sociología.

\section{A DIMENSÃO EPISTEMOLÓGICA DA TRANSDISCIPLINARIDADE EM NOSSA PERSPECTIVA}

\begin{abstract}
proposta transdisciplinar se apresenta como uma força de produção humana a partir do fim da década de 1990, mesmo que se possa identificar, já no fim 1 da década de 1970, algumas orientaçôes dedicadas a superar o disciplinar, o multidisciplinar e o interdisciplinar, como veremos mais adiante. O Manifesto da Transdisciplinaridade, escrito por Nicolescu (1999), propõe uma nova posição dos homens em relação aos outros homens e à natureza. Ainda que, para alguns, "se trate mais de uma promessa remetida ao futuro do que uma realidade efetiva" como afirma Julie Klein, uma das maiores autoridades no assunto (Domingues, 2012), não podemos negar a força de originalidade do manifesto. Mesmo assim, consideramos importante pensar sobre os antecedentes históricos e conceituais dessa ideia.
\end{abstract}


Para Nicolescu (2000), é difícil precisar o ponto de origem do termo "transdisciplinaridade". Segundo o autor, poderíamos localizar em Niels Bohr, no ano de 1955, o primeiro uso da palavra. Todavia, segundo Iribarry (2003), "a fonte mais segura é um documento redigido por Piaget (1972 apud Japiassu, 1976) em um colóquio da UNESCO, de 1972” (p. 485). Nesse documento, Piaget anunciaria a necessidade de se ultrapassarem as relaçôes interdisciplinares em direção à construção de uma transdisciplinaridade. Fundamentado na hipótese de que se pode atribuir a Piaget a introdução do conceito de transdisciplinaridade, Iribarry (2003) defende a importância da obra do maranhense Japiassu para as produções brasileiras sobre o conceito e a prática transdisciplinar.

Não pretendemos investigar neste texto a origem precisa ${ }^{5}$ do termo; interessanos compreender a ideia da transdisciplinaridade e localizar a vertente filosófica que possibilitou esse salto de uma ciência disciplinar descritiva para uma ciência implicada com a prática e que tem impacto direto na construção do conhecimento. Como descreve Domingues (2012), em sua concepção da transdisciplinaridade:

Trata-se do modo de produção de conhecimento de tipo II, que, diferentemente do tipo I, caracterizado por cindir conhecimento e sociedade e separar ética e ciência, ata aqueles dois, formata o conhecimento socialmente robusto e interpela pela responsabilidade individual e coletiva dos cientistas (p. 21).

Segundo Silva (2007), o Manifesto da Transdisciplinaridade estabelece como alvo crítico o processo de fragmentação do conhecimento, as falsas dualidades "sujeito/objeto, subjetividade/objetividade, atéria/consciência, natureza/divino, simplicidade/complexidade, reducionismo/holismo, diversidade/unidade, com o reconhecimento da existência de complexas pluralidades no mundo da vida" (p. 138). Reconstruindo o raciocínio de Nicolescu, o citado autor discute a importância, o alcance e a capilaridade das ideias desse pensador no âmbito da educação, por exemplo, posto que sua contribuição expressa nas ideias contidas em o Manifesto da transdisciplinaridade foi fundamental para a formulação dos quatro pilares do novo tipo de educação proposto pela UNESCO ${ }^{6}$ através do Relatório Delors. Esses pilares são: "aprender a conhecer", "aprender a fazer", "aprender a conviver" e "aprender a ser". "Aprender a conhecer" se refere à necessidade de respeito ao compromisso com a conexão entre diferentes saberes; "aprender a fazer" implica a noção de criatividade e a força para transpor os limites;

5 Ainda que saibamos que este tema está em ampla relação com um possível deslocamento ou avanço de relações interdisciplinares que, para o caso, o mesmo Piaget identificava como característica própria do campo da epistemologia genética, que teve seu auge depois da segunda metade do século XX, graças ao patrocínio dado, em 1955, pela Fundação Rockefeller com a fundação, em Genebra, do chamado Centro Internacional de Epistemologia Genética (Piaget, 1970). Esse centro conseguiu realizar inúmeras pesquisas, instaurando um amplo campo de conhecimento em cognição humana.

6 UNESCO (Organização das Nações Unidas para a Educação, a Ciência e a Cultura). Agência especializada da Organização das Nações Unidas (ONU) com o objetivo de contribuir para a paz e segurança no mundo mediante a educação, ciências naturais, ciências sociais/humanas e comunicações/informação. 
“aprender a conviver", segundo Silva (2007), “deve significar o respeito pelas normas que regem as relações entre os seres que compõem uma coletividade, mas essas normas precisam ser compreendidas, partilhadas e validadas pela experiência interior de cada ser" (p. 139). E, por fim, "aprender a ser" corresponde a um movimento permanente de abertura ao novo, que possibilita a ressignificação.

Assim, segundo Nicolescu (1999),

A transdisciplinaridade, como o prefixo "trans" indica, diz respeito àquilo que está ao mesmo tempo entre as disciplinas, através das diferentes disciplinas e além de qualquer disciplina. Seu objetivo é a compreensão do mundo presente para o qual um dos imperativos é a unidade do conhecimento (p. 22).

Os imperativos anunciados por Nicolescu de compreender e agir considerando a coletividade anunciam a posição ética da proposta transdisciplinar, sendo a ética uma exigência que pensa a convivência entre os diferentes. A proposta é ultrapassar o modelo estabelecido de ciência e teorização para acolher um modelo que valorize e integre as diversas formas de produção de conhecimento.

\section{A PERSPECTIVA DA ESCOLA DE FRANKFURT}

Podemos dizer que um passo nesse sentido foi dado por Horkheimer e Adorno (1980), ao criticarem o modelo positivista de teoria e ciência. Em Teoria tradicional e teoria crítica (1980b), os autores iniciam sua reflexão perguntando: "O que é a teoria?". A seguir, algumas respostas são apresentadas: primeiramente, pensa-se a teoria como uma sinopse de proposições e princípios de um campo; em seguida, discute-se a teoria como um saber acumulado, nos moldes de um catálogo, de uma biblioteca. Assim,

Sua validade real reside na consonância das proposiçōes deduzidas com os fatos ocorridos. $\mathrm{Se}$, ao contrário, se evidenciam contradiçōes entre a experiência e a teoria, uma ou outra terá que ser revista. Ou a observação falha, ou há algo discrepante nos princípios teóricos (Barreto, 2001, p. 37).

As pretensões de universalização da teoria tradicional podem produzir ações violentas sobre os objetos estudados, mas esta violência é intensificada quando se transporta esse raciocínio para as Ciências Humanas. Por isso talvez seja importante voltar, como expressa Gadamer (2001), ao "sentido original da expressão grega Theoria" quando se lhe atribuía a condição de "algo importante", retirando-se as barreiras entre a ciência tradicional, que "teoriza a verdade", e as outras ciências que especulam. Assim poderemos falar do diálogo entre saberes, elemento importante para o desenvolvimento das ciências, mas, antes de tudo, 
do conhecimento em geral.

Voltando a Horkheimer e Adorno (1980b), os autores argumentam que

Ciências do homem e da sociedade têm procurado seguir o modelo das bem-sucedidas ciências naturais. São os métodos de formulação exata, especialmente métodos matemáticos, cujo sentido está em estreita conexão com conceito de teoria esboçado acima, que são muito apreciados por estes cientistas (p. 119).

Horkheimer e Adorno (1980b) esclarecem que "Não é o significado da teoria geral que é questionado aqui, mas a teoria esboçada de cima para baixo" (p. 119). A teoria tradicional estaria vinculada à tarefa de descrever, catalogar, prever e controlar a partir dos resultados. Assim, o trabalho seria calcado na ideia de uma reprodução contínua, uma força de manutenção do que é, autopreservação de interesses. Podemos pensar que se segue o princípio de que este mundo existe e deve ser aceito. Como afirmam os autores, "O conceito da teoria é independentizado, apresenta uma fundamentação a-histórica" (Horkheimer \& Adorno, 1980b, p. 125, grifo nosso). Assim, "os fatos que os sentidos nos fornecem são pré-formados de modo duplo: pelo caráter histórico do objeto percebido e pelo caráter histórico do órgão perceptivo" (p. 125). Ademais, "o fato percebido antes mesmo da sua elaboração teórica consciente por um devido cognoscente já está codeterminado pelas representaçôes e conceitos humanos" (Horkheimer \& Adorno, 1980b, p. 125).

A teoria crítica da sociedade se localiza na posição oposta da lógica da reprodução. A proposta da teoria crítica é analisar "o que é" para produzir a reflexão que trabalha "o como deveria ser". Assim, a proposta se fundamenta na ideia de que "os homens são produtores de todas as suas formas históricas de vida" (Horkheimer \& Adorno, 1980b, p. 155). A forma como as relações se efetivam não é, apenas, um fato dado, mas se articula com o poder do homem de modificá-las. A percepção do homem sobre a realidade, a capacidade de formulação de questões e o sentido da resposta são provas da atividade humana e do grau de poder do homem de modificar as realidades sociais e promover a emancipação das situações de aprisionamentos materiais, psíquicos e sociais. Parece-nos importante salientar que o poder para a transformação se localiza, sobretudo, nos sujeitos, mas não podemos descartar o diálogo desses sujeitos com as teorias, um ponto crucial para o trabalho transdisciplinar. Ainda segundo os autores, "a teoria crítica não almeja de forma alguma apenas uma mera ampliação do saber, ela intenciona emancipar o homem de uma situação escravizadora" (Horkheimer \& Adorno, 1980b, p. 156).

É importante ressaltar que a nova geração da teoria crítica, especificamente 
Honneth (1996), considera que os estudos de Horkheimer apresentam um déficit sociológico. Para o pensador, a reflexão de Horkheimer e Adorno não oferece uma proposta efetiva de transformação, visto que suas investigações teóricas sobre a realidade carecem de uma modulação empírica. Com um desejo de retificação, na teoria sobre a luta pelo reconhecimento no interior das regras que determinam as relaçóes humanas, ou na gramática dos conflitos sociais, Honneth (1996) propõe uma articulação da teoria do reconhecimento do jovem Hegel $(1801,1803)$ com a Psicologia social de G. H. Mead e a psicanálise winnicottiana. Para Honneth (1996), encontraremos em Mead uma concepção pós-metafísica da teoria do reconhecimento. Assim a teoria honnethiana anuncia que os sujeitos se localizam a partir de três dimensóes de reconhecimento (no amor, no direito e na solidariedade) e que, em Mead, essas dimensões se referem às relações primárias, às relações jurídicas e ao trabalho.

Não podemos afirmar que encontramos na teoria crítica da sociedade, seja no modelo de Horkheimer ou no de Honneth, uma proposta transdisciplinar. Todavia o Instituto de Pesquisa Social, originariamente fundando em Frankfurt por Horkheimer e atualmente dirigido por Honneth, propõe um diálogo interdisciplinar no sentido forte, ou seja, uma troca intersubjetiva entre filósofos, sociólogos, psicanalistas e outros, buscando-se, dessa forma, pensar e intervir na realidade.

\section{UMA COLABORAÇÃO DA ANTROPOLOGIA}

A modulação empírica que faltava à teoria crítica estava presente na disciplina antropológica desde seus primórdios. No entanto, até o século XIX, existia uma distinção entre os antropólogos (aqueles que construíam as pretensas teorias gerais sobre a humanidade) e os etnólogos (aqueles missionários, comerciantes e agentes coloniais que se dedicaram a descrever e traduzir os costumes nativos). Segundo Clifford (1998), a fusão dessas duas figuras se deu em prol de um ideal de ciência positivista, uma vez que os antigos etnólogos começaram a ser malvistos pelos antropólogos por não terem embasamento científico nem a pretensa neutralidade a que normalmente se associa o trabalho científico.

Assim, autores como Bronislaw Malinowski, Margaret Mead eAlfred RadcliffeBrown construíram uma série de recomendações metodológicas que, se fossem seguidas, permitiam a formação de um conhecimento objetivo e neutro sobre as culturas nativas pesquisadas. Entre essas recomendaçôes estava a crença no poder da abstração teórica e principalmente o foco na observação, uma vez que a cultura aqui era entendida como um conjunto de comportamentos, cerimônias e gestos que pode ser apreendido por um observador bem treinado. Temos assim, 
uma ênfase na autoridade da experiência: o antropólogo "esteve lá" e produziu um conhecimento neutro e objetivo.

Apesar dessa crença na objetividade do conhecimento, os pesquisadores assumiam uma posição de cumplicidade com as práticas imperialistas, tratando a figura do nativo de forma exótica. Além disso, havia a ideia de que a etnografia deveria criar uma peça monumental da cultura descrita, que era encarada a partir de concepçôes sincrônicas. A cultura se reduz a um objeto inerte em um museu ou numa biblioteca (Denzin \& Lincoln, 1998).

A partir da década de 1960, a antropologia passou a enfrentar uma intensa crise de caráter político e epistemológico. No contexto histórico das agitaçôes estudantis no mundo, do movimento de direitos civis estadunidense e das lutas pela independência dos países da África, essa disciplina foi denunciada como instrumento da dominação colonial de povos nativos mundo a fora. Outro marco importante foi a publicação póstuma do diário pessoal de Malinowski, em 1967, o qual foi escrito durante as experiências de campo do antropólogo e, ao contrário dos livros publicados por ele, revela suas tristezas, preocupações e principalmente seus preconceitos (e até mesmo antipatia) em relação aos nativos que estudava. O contraste entre o que está na obra Argonautas do Pacífico Ocidental (Malinowski, 1978) e o que está no diário levantou sérias dúvidas sobre a sinceridade dos escritos etnográficos e sobre o ideal positivista de neutralidade do conhecimento.

Os movimentos intelectuais desse contexto, como a Virada Linguística e a Virada Cultural, passaram, assim, a questionar a objetividade e a autoridade interpretativa dos antropólogos. Nesse quadro, houve a revisão das perspectivas positivistas, que dão lugar a visões mais amplas, pluralistas e interpretativas. Dessa maneira, é preciso descrever de maneira densa eventos, rituais e costumes, tendo a consciência de que qualquer escrito antropológico é, no máximo, uma interpretação da interpretação, sendo que o observador não tem voz privilegiada naquilo que foi escrito (Denzin \& Lincoln, 1998).

Nesse sentido, é preciso destacar a visão de Clifford (1998), para quem a etnografia como experiência textualizada está separada do seu contexto original, o que dá a ela um caráter literário. Segundo esse autor "A escrita etnográfica é alegórica tanto no nível de seu conteúdo (o que ela diz sobre as culturas e suas histórias) quanto no de sua forma (as implicações de seu modo de textualização)" (Clifford, 1998, p. 59).

Essa ideia se afasta muito dos ideais positivistas de neutralidade, objetividade, distanciamento de julgamentos morais e principalmente de desinteresse. Desse modo, o método da observação participante passou a ser visto como misto 
de experiência pessoal e análise científica, associando, portanto, experiência subjetiva e experiência objetiva. Assim, a etnografia passa a ser compreendida como uma história que tem função pedagógica ou explicativa, mas que também pode mistificar ou exotizar os seus objetos.

A revisão das perspectivas positivistas introduziu a necessidade de lógicas dialógicas e polifônicas entre pesquisadores e sujeitos de pesquisa. Essas lógicas encaram a empreitada do conhecimento como "uma negociação construtiva envolvendo pelo menos dois, e muitas vezes mais sujeitos conscientes e politicamente significativos" (Clifford, 1998, p. 43). Rompe-se, assim, com a monopolização discursiva e a autoridade baseada no conhecimento acadêmico dos antropólogos de outrora.

Talvez um dos grandes exemplos contemporâneos seja a colaboração entre o líder ianomâmi Davi Kopenawa e o antropólogo marroquino Albert (Kopenawa, \& Albert, 2010) em $A$ queda do céu. Essa obra relata o modo de vida e a visão cosmopolítica da comunidade Ianomâmi e os conflitos e contrastes com a cultura ocidental a partir do diálogo entre Kopenawa e Albert. Trata-se de uma prática de alteridade radical, baseada na recusa da ideia de que a ciência é formada por um sujeito ativo que detém o conhecimento e um sujeito passivo que pode ser investigado. Muito pelo contrário: "Sua produção, oral e escrita, foi, portanto, constantemente atravessada pelas visadas discursivas cruzadas de seus autores, um xamã Yanomami versado no mundo dos brancos e um etnógrafo com longa familiaridade com o de seus anfitriôes" (Kopenawa \& Albert, 2010, p. 51).

Iniciativas como essa dentro da Antropologia têm promovido a construção de conhecimentos que estão além dos campos disciplinares fechados, pois valorizam as pontes estabelecidas entre os saberes tradicionais e acadêmicos.

\section{A DIMENSÃO EMPÍRICA DA DISCUSSÃO EPISTEMOLÓGICA DA NOÇÃO DE TRANSDISCIPLINARIDADE}

Segundo Leff (2000), é importante considerar a proposta transdisciplinar como uma crítica ao logocentrismo fundante da ciência moderna, que descartou do campo do conhecimento legítimo todo saber não científico. Segundo o autor:

A transdisciplinaridade é o questionamento do logocentrismo e da configuração paradigmática do conhecimento, do qual erradicou da ciência normal todo saber não científico como externo e estranho, como patológico, como "não conhecimento"; é a transgressão da disciplinaridade, do saber codificado para apreender (Leff, 2000, p. 33).

Podemos dizer, a partir do que argumenta Herrán (2013), que a transdisciplinaridade é um movimento da ciência (assim como o disciplinar, o 
multidisciplinar e o interdisciplinar) que tem como alvo "se ocupar da realidade" (p. 5, tradução nossa), adiantando um processo de "tomada de consciência" do que se sabe e do que se ignora; essa tomada de consciência é descrita pelo autor da seguinte forma:

No contexto de uma pesquisa transdisciplinar [. . . ] diante de uma ciência, um escopo, um tema, uma questão ou uma situação objeto de pesquisa, se admitam a incompletude, a falibilidade e os limites da própria disciplina e do pesquisador ou da equipe, e que essa admissão esteja amoldada pela dúvida, a humildade científica e o estar aberto para aquilo do que se tem carência ou se pode ou não compartilhar. Não pode se dar de outra forma essa abertura, nem pode se começar de outra forma o processo de conhecimento que de fato está constituído pela dúvida mesma. Essa antessala é efeito da boa formação científica (Herrán, 2013, p. 6, tradução nossa).

Com o mesmo Herrán, podemos dizer que de mãos dadas ao logocentrismo está o egocentrismo dos pesquisadores que inflam as disciplinas e se inflam delas. Nessa perspectiva, a proposta da transdisciplinaridade é também uma crítica a essa tendência egocêntrica e "de imaturidade pessoal de agentes pesquisadores" (Herrán, 2013, p. 5, tradução nossa) que não permitem perceber o que há para além das paredes disciplinares.

A prática "trans" expressa o desejo da interação entre as fronteiras dos saberes formais e informais. Segundo Vasconcelos (2009), as "práticas trans-" significam a interação entre as fronteiras de campos de saber e fazer, tanto formais como informais, como na interação com o campo da arte e com o senso comum e, ou, cultura popular (Vasconcelos, 2009, p. 4). Esse diálogo aberto e democrático com todo campo de saber formal e informal pode produzir no profissional o receio da perda da identidade profissional, mas é importante estar atento para a necessidade de abertura ao movimento pendular que, a partir de sua identidade profissional, intervém no caso e, ao mesmo tempo, abre-se para escutar e acolher o saber que vem do campo do outro. Esse "movimento pendular" enriquece a apreensão da realidade e seria uma das condiçóes para uma ação ou projeto se afirmar como uma abordagem "trans" segundo nos informa a Carta da transdisciplinaridade, em seu Artigo 4:

A pedra angular da transdisciplinaridade reside na unificação semântica e operativa das acepçôes através e além das disciplinas. Ela pressupõe uma racionalidade aberta, mediante um novo olhar sobre a relatividade das noçôes de definição e de objetividade. O formalismo excessivo, a rigidez das definiçôes e o exagero da objetividade, incluindo-se a exclusão do sujeito, conduzem ao empobrecimento (Freitas, Morin, \& Nicolescu, 1994, p. 2).

Em Domingues (2012), identificamos a descrição da transdisciplinaridade como uma potente abordagem que vai além das disciplinas e, por sua "índole 
transgressora”, busca quebrar barreiras e desobedecer às regras, mas nem por isso seria refratária a críticas ou imune aos tropeços do fazer humano.

Assim, segundo Klein (1990), a transdisciplinaridade é mais "compreensiva em escopo e visão", tendo como objetivo fornecer sínteses teóricas abrangentes capazes de unificar o conhecimento [...]. O essencial é entender que o disciplinar, o multi, o inter e o trans são formas de organização e difusão do conhecimento e, como tais, não têm nada de necessário ou sacrossanto. De fato, são criações históricas e culturais e, enquanto tais, contingentes (Domingues, 2012, p. 15).

Domingues busca explicar a transdisciplinaridade por meio da aproximação com outras abordagens, no caso "multi" e interdisciplinar, mas admite que, por sua radicalidade e "pela exigência de promover uma dupla coordenação horizontal e vertical da pesquisa" (Domingues, 2012, p. 15), a abordagem "trans" talvez se aproxime mais de um novo paradigma científico que de um método ou perspectiva metodológica. Isso implica uma torção mais radical, complexa e abrangente que não se reduz, como vimos, a procedimentos metodológicos.

Breda e Swilling (2016), reconstruindo o pensamento de Stokols, Hall e Vogel (2013), apresentam a transdisciplinaridade como:

Um processo integrador pelo qual acadêmicos e profissionais que representam diferentes disciplinas e epistemologias trabalham em conjunto para desenvolver e usar novas abordagens conceituais e metodológicas, que sintetizam e ampliam teorias, métodos e estratégias translacionais específicos para disciplinas, para produzir soluções inovadoras para problemas sociais (Stokols, Hall, \& Vogel apud Breda \& Swilling, 2016).

Ao anunciarem as principais características da transdisciplinaridade, os autores produziram o esquema a seguir, em que caracterizam a transdisciplinaridade de cinco diferentes formas:

Colaborativa - promove superação dos limites disciplinares.

Transformativa - voltada para a busca de soluções (conhecimento útil).

Integrativa - integra o conhecimento produzido por meio de novos métodos.

Inovadora - desenvolve novas maneiras de compreender e construir teorias por meio da coprodução. Além disso, possui 1) conhecimento do sistema - o que "é" (conhecimento factual); 2) conhecimento do objetivo - o que deve ser (conhecimento normativo); 3) conhecimento transformativo - como é a transição do que se é ao que se busca ser (conhecimento estratégico).

Igualitária - trata todo conhecimento, teórico e prático, com igual valor (Breda \& Swilling, 2016, tradução nossa). 
Dessa forma, Breda e Swilling (2016) defendem que a transdisciplinaridade precisa se assentar em ações pragmáticas, relacionais e construtivistas na solução integrada para problemas complexos. Para tanto é necessária uma metodologia que operacionalize tais conviç̧óes. No documento Transdisciplinary research for transformation in an African context, organizado pelos autores citados, são apresentados os princípios metodológicos que orientam a prática "trans":

10 Princípio: Reduzindo a complexidade: desenvolver uma compreensão conjunta dos problemas complexos na linguagem cotidiana [por exemplo, via narrativa]; a tradução do entendimento compartilhado cotidiano aborda as declaraçôes teóricas de problemas e questōes de pesquisa [objetos epistêmicos];

20 Princípio: Contextualização do TDR por incorporação em dois contextos: contexto social/cotidiano do mundo da vida: onde a mudança/transformação social das situaçōesproblema precisa ocorrer (indigenização); contexto científico/teórico: onde novas questōes de pesquisa, conhecimento teórico e métodos integrativos de pesquisa sobre os complexos problemas do mundo real precisam ser continuamente coproduzidos.

Conseguir a integração e inovação do conhecimento através de:

$3^{\circ}$ Princípio: Reflexividade e recursividade durante todas as fases e passos do processo de TDR, assegurando que o aprendizado "individual" ou "social" seja atendido pelo processo de TDR e que contribua para o projeto emergente do processo; processo iterativo.

40 Princípio: Aceitação da equidade de todos os sistemas de conhecimento: enfrentamento dos problemas de ética nos problemas teóricos/científicos e práticos/experienciais de valores equivalentes (Breda \& Swilling, 2016, tradução nossa).

Finalmente, entendemos, com Iribarry (2003), que

A transdisciplinaridade deve ser encarada como meta a ser alcançada e nunca como algo pronto, como um modelo aplicável, e como um desafio que serve de parâmetro para que todos os membros da equipe estejam atentos para eventuais cristalizações e centralizações do poder (p. 488).

Com Nicolescu, por sua vez, aprendemos que "Sem uma metodologia, a transdisciplinaridade seria uma proposta vazia", mas que trabalha apoiada em três pilares: a realidade, compreendida como "aquilo que resiste a nossas experiências, representações, descrições, imagens ou formalizações matemáticas" (Nicolescu, 2000, p. 17); a complexidade, que supõe a coexistência de todas as disciplinas em interação; e, por fim, o terceiro incluído, ou, nas palavras de Nicolescu, "o próprio indivíduo". 


\section{QUESTÕES CONCERNENTES AO PROJETO SOBRE TRAJETÓRIAS E NARRATIVAS DE ADOLESCENTES AUTORES DE ATO INFRACIONAL}

Nosso projeto pretende investigar, a partir da transdisciplinaridade (em que se conectam os saberes da Sociologia, da Psicanálise, do Direito, da Educação e da Saúde), o curso de vida de jovens em vulnerabilidade acolhidos pelo sistema socioeducativo, a fim de identificar eventos que expliquem a relação do adolescente com a delinquência: a entrada, a permanência ou não permanência, a desistência ou não desistência. Assim, o ponto central de nosso estudo é o adolescente envolvido com a criminalidade, o que faz com que tenhamos, pois, dois conceitos por excelência transdisciplinares: adolescência e criminalidade. E nosso modo de aproximação desse problema da realidade brasileira é através da metodologia das narrativas e da trajetória de vida como estratégia para recolher também o saber dos jovens participantes dessa pesquisa sobre seu próprio percurso.

Cabe destacar que os dois eixos fundamentais desta pesquisa, quais sejam, adolescência e criminalidade, são conceitos que convocam vários saberes por sua complexidade e infinidade de dimensões e aspectos que giram em torno desse binômio. Tais saberes serão aqui articulados a partir da noção de desistência, a principal questão que se pretende compreender. As narrativas e trajetórias constituem parte do arcabouço metodológico que busca inserir o saber do sujeito "No ponto de encontro do diálogo transdisciplinar entre a teoria da criminologia do curso de vida, derivada da sociologia, por um lado, e as apostas inconscientes do sujeito implicados nas suas escolhas, por outro" (Instituto de Estudos Avançados Transdisciplinares da Universidade Federal de Minas Gerais, 2017, p. 6). Busca-se, pois, por meio da coprodução, aproximar todos esses saberes (práticos e teóricos) e perspectivas de uma realidade tão complexa e violenta.

A necessária análise da conjuntura sociossubjetiva e político-discursiva que qualifique, como plano de fundo, a análise da criminalidade e da mortalidade juvenis, em especial em Minas Gerais, lembrando-nos que há processos sociais e simbólicos nela implicados, além dos processos subjetivos, econômicos e políticos que envolvem o próprio jovem. Face a esse quadro, colocamo-nos a trabalho nessa pesquisa interdisciplinar que visa, retomando a literatura clássica sobre curso e trajetórias de vida, atualizar com dados empíricos a análise da trajetória infracional de jovens em situação de vulnerabilidade, buscando localizar os turning points que demarcam momentos decisivos para entrada, permanência ou desistência da relação com o crime. Essa metodologia pode ser orientadora para ações em políticas públicas voltadas à juventude brasileira (Instituto de Estudos Avançados Transdisciplinares da Universidade Federal de Minas Gerais, 2017, p. 6). ${ }^{7}$

7 Curso de vida e trajetória delinquencial: um estudo exploratório dos eventos e narrativas de jovens em situação de vulnerabilidade. (Edital 2017. Instituto de Estudos Avançados Transdisciplinares Universidade Federal de Minas Gerais - 
O Mapa da violência (Waiselfisz, 2016), no item Mortes matadas por armas de fogo, estuda o período de 1980 a 2012, contabilizando 880.386 vítimas de disparos de armas de fogo, número superior ao encontrado em países em situação de guerra ou conflito civil. Esses dados alarmantes são, então, a motivação para a construção deste projeto transdisciplinar, que se articula como compromisso ético, em que somos movidos pelo desejo de intervir nesse triste cenário de mortalidade juvenil. Assim, tem-se uma meta transdisciplinar por meio da qual esperamos, pelo diálogo, produzir ações pragmáticas, relacionais e construtivistas na solução integrada para o complexo problema do envolvimento de jovens com a criminalidade.

No entanto, para além do necessário e desafiador diálogo interdisciplinar que articule os vários saberes, a transdisciplinaridade nos convoca a incluir o saber do sujeito em observação, alçando-o do lugar de "objeto de estudos" ao de sujeito do próprio saber. Isso significa reconhecer que o sujeito tem um saber não formal sobre si e sobre sua realidade, que deve compor, em diálogo com as demais disciplinas, o conhecimento científico acerca da temática desenvolvida em pesquisa. A prática "trans" também pressupõe transformação da realidade, transformação essa que exige a perspectiva dos que estão diretamente envolvidos. Não se trata, pois, de uma mera interpretação, análise ou teorização.

Nesse ponto, nós nos concentramos em uma questão fundamental e ainda em construçãop paraaatividadequeestamos desenvolvendo. Comopensarteoricamente a inclusão dos sujeitos no exercício e execução da atividade de pesquisa? Onde e como entraria o saber informal do jovem, de maneira a sustentar radicalmente o modelo conceitual e metodológico proposto pela transdisciplinaridade? Essa parece ser uma linha d'água entre a transdisciplinaridade e as demais perspectivas epistemológicas.

A participação do sujeito pode trazer grandes sobressaltos aos que dão às teorias o estatuto de verdade incontestável e temem o contraditório, mas Nicolescu (2000) insiste:

$\mathrm{Na}$ lógica do terceiro incluído $o$ indivíduo os opostos são antes contraditórios: a tensão entre os contraditórios promove uma unidade que inclui e vai além da soma dos dois termos. [. . .] O indivíduo permanece estranhamente calado diante da compreensão da complexidade por parte dos teóricos. E com razão, pois fora declarado morto. Entre as duas extremidades do bastão - simplicidade e complexidade -, falta o terceiro incluído: o próprio indivíduo (pp. 11-14, grifos nossos).

Se para a ciência clássica a possibilidade de fazer falar o sujeito se estabelece a partir do modelo "trans", para a psicanálise este ponto, ou, a posição do sujeito, 
está posta desde sempre como questão ética, e mesmo no sentido de sua existência, afinal Freud jamais prescindiu do discurso de seus pacientes e, a partir deles, construiu uma teoria robusta e consistente. Moreira, Oliveira e Costa (2018), ao discutirem Sauret (2003) e Pinto (2009), afirmam que é justamente a presença do sujeito o fator assimétrico entre a pesquisa na ciência positivista e a pesquisa em psicanálise.

Sauret (2003), entretanto, expõe a contraposição do método psicanalítico ao método científico ao apontar o lugar que o sujeito ocupa em ambas as metodologias. Para a autora, o sujeito é excluído do método científico, pois sua presença é incompatível com os parâmetros de objetividade, generalização e universalidade exigidos pela ciência positivista. Assim, o método científico condiciona sua veracidade à neutralidade do sujeito que produz o saber e à objetificação do outro sujeito da pesquisa. A psicanálise, ao contrário, não renuncia ao sujeito, mas tem no sujeito do inconsciente seu próprio fundamento. Para Pinto (2009), a psicanálise não se contrapõe à ciência, mas vem subverter o lugar do sujeito no discurso científico, na medida em que, ao ter como objeto o inconsciente, aponta para o que escapa ao discurso da ciência, tratando daquilo que não se dá a conhecer (Moreira, Oliveira, \& Costa, 2018).

Assim, afirmamos que a presença do sujeito nas pesquisas em psicanálise ou orientadas por essa corrente teórica é da ordem de um estatuto. Contudo, quando consideradas as proposições da transdisciplinaridade, percebemos alguma diferença quanto à densidade dessa presença. A transdisciplinaridade parece propor algo bem menos mediado pelo pesquisador e suas teorias, reconhecendo, no discurso do sujeito, um novo estatuto de saber, com força, inclusive, de contraponto às teorias tradicionais.

O que nos interpela em relação à transdisciplinaridade talvez seja o fato de que, em psicanálise, assumimos abertamente o envolvimento do pesquisador e o entrelaçamento intersubjetivo (que Freud nomeia por "transferência") nas construções científicas desenvolvidas por nós, sendo o discurso e posição do sujeito, em alguns casos, encapsulado pelo saber psicanalítico. Rosa e Domingues (2010) citados por Moreira, Oliveira e Costa (2018) para comentarem essa relação:

Operar com o inconsciente implica, pois, a suposição de um saber que "não se sabe", mas que é suposto. As condições de produção de conhecimentos sobre este "insabido" são internas ao campo relacional que o constitui. A isso denominamos em psicanálise "transferência". Não é, pois, um saber prévio que já estava ali, no "entrevistado", como um dado a ser colhido pelo "entrevistador". É algo que se situa num espaço transferencial em que o "insabido" se expressa como formaçôes do inconsciente. Logo, ele inclui o pesquisador na própria formação (Rosa \& Domingues, 2010, p. 186, apud Moreira, Oliveira \& Costa, 2018).

A pesquisa científica orientada pela psicanálise reconhece no sujeito do 
inconsciente essa fonte de saber que pode ser reinventado a cada "ponto do impossível". Para Moreira, Oliveira, e Costa, "O pesquisador que se depara com uma lacuna no conhecimento a toma como motor de seus esforços investigativos, assim como o analisante é movido a partir daquilo que não pode significar, mas que não deixa de surtir efeitos" (Moreira, Oliveira, \& Costa, 2018). Nessa perspectiva, o "pesquisador-analisante" supõe o saber em seu objeto de pesquisa e não recua diante do impossível, mas constrói nova borda dentro das possibilidades que inventa.

Acreditamos que será da ordem da invenção nossas respostas às questões relacionadas anteriormente, as quais se tornarão ainda mais provocadoras na ocasião da análise dos dados que nos chegam do campo. Contudo reafirmamos nossa determinação em aproximar o quanto possível, por meio de ações inovadoras, as diversas perspectivas, seja no campo acadêmico, seja no campo do saber não científico que emerge da produção oral dos participantes da pesquisa.

Concluímos, assim, essas considerações em que buscamos aproximar as proposições da teoria crítica e da transdisciplinaridade com algumas questóes que vêm balizando nossos estudos e nossa atuação sem a pretensão de respondêlas precocemente. Pelo contrário, talvez seja necessário atualizá-las a cada novo caso a ser analisado e, para cada novo cenário, questionarmos: qual seria o limite entre a transformação/transposição do discurso do jovem em (para uma) questão de pesquisa e a interpretação do pesquisador? Essa é uma questão relevante ou é um processo inevitável? Como fazer uso dos aportes teóricos das disciplinas envolvidas construindo um novo conjunto de conceitos que se reconheça em ambos os campos?

Acreditamos que uma aposta no projeto emancipatório deve necessariamente manter tais questões no horizonte de pesquisa e ação no campo social, buscando alcançar respostas a cada volta, sem se comprometer com afirmações definitivas. 


\section{REFERÊNCIAS}

Barreto, T. V. (2001). Positivismo versus teoria crítica em torno do debate entre Karl Popper e Theodor Adorno acerca do método das ciências sociais. Trabalhos para discussão, 106, mar. 2001. Recuperado a partir de https://ayanrafael.files. wordpress.com/2011/08/barreto-t-positivismo-versus-teoria-crc3adtica-emtorno-do-debate-entre-karl-popper-e-theodor-adorno-acerca-do-mc3a9tododas-cic3aancias-sociais.pdf

Breda, J. V. \& Swilling, M. (2016). Transdisciplinary research for transformation in an African context. Stellenbosch: CST, Stellenbosch University. Recuperado a partir de http://markswilling.co.za/wp-content/uploads/2016/07/Coventry2. pdf.

Clifford, J. (1998). Sobre a autoridade etnográfica. In A experiência etnográfica: antropologia e literatura no século XX. (pp. 17-62). Rio de Janeiro: Editora UFRJ.

Denzin, N. \& Lincoln, Y. (1998). Introduction: entering the field of qualitative research. In N. Denzin \& Y. Lincoln. Strategies of Qualitative Inquiry. (pp. 1-34). Thousand Oaks: Sage.

Domingues, I. (2012). Multi, inter e transdisciplinaridade: onde estamos e para onde vamos? Pesquisa em Educação Ambiental, 7(2), 11-26.

Instituto de Estudos Avançados Transdisciplinares da Universidade Federal de Minas Gerais. Edital 2017. Belo Horizonte: IEAT, UFMG. Recuperado a partir de: https://www.ufmg.br/ieat/wp-content/uploads/2017/01/EditalGrupos-de-Pesquisa-2017.pdf

Freitas, L., Morin, E., \& Nicolescu, B. (1994). Carta da transdisciplinaridade. Convento da Arrábida, 6 de novembro de 1994. São Paulo: Cetrans. Recuperado a partir de http://cetrans.com.br/assets/docs/CARTA-DATRANSDISCIPLINARIDADE1.pdf

Gadamer, H. (2001). Palabra e imagen: "así de verdadeiro, así de óntico". In Antologia. Salamanca: Sigueme.

Herrán, A. (2013). ¿Una transdisciplinariedad inmadura? Consideraciones críticas radicales (pensando desde la Pedagogía y la Didáctica). In J. Paredes, F. Hernández \& J. M. Correa (Ed.), La relación pedagógica en la universidad, lo transdisciplinar y los estudiantes: desdibujando fronteras, buscando puntos de encuentro. Madrid: Universidad Autónoma de Madrid. 
Honneth, A. (1996). Luta por reconhecimento: a gramática moral dos conflitos sociais. São Paulo: Ed. 34.

Horkheimer, M. \& Adorno, T. (1980a). Filosofia e teoria crítica. In W. Benjamin et al. Textos escolhidos. São Paulo: Abril Cultural, 1980. (Coleção Os Pensadores).

Horkheimer, M. \& Adorno, T. (1980b). Teoria tradicional e teoria crítica e Filosofia e teoria crítica. In W. Benjamin et al. Textos escolhidos. São Paulo: Abril Cultural, 1980. (Coleção Os Pensadores).

Iribarry, I. N. (2003). Aproximações sobre a transdisciplinaridade: algumas linhas históricas, fundamentos e princípios aplicados ao trabalho de equipe. Psicologia: reflexão e crítica, 16(3), 483-490. Recuperado a partir de http:// www.scielo.br/pdf/prc/v16n3/v16n3a07

Japiassu, H. (1976). Interdisciplinaridade e patologia do saber. Rio de Janeiro: Imago.

Kopenawa, D. \& Albert, B. (2015). A queda do céu: palavras de um xamã yanomami. B. Perrone-Moisés (Trad.). São Paulo: Companhia das Letras.

Leff, E. (2000). Complexidade, interdisciplinaridade e saber ambiental. In A. Philippi Júnior. Interdisciplinaridade em Ciências. São Paulo: Signus. Recuperado a partir de http://www.unievangelica.edu.br/files/images/ Interdisciplinaridade $\% 20 \mathrm{e} \% 20 \mathrm{Ci} \% \mathrm{C} 3 \% \mathrm{AAncias} \% 20 \mathrm{Ambientais} \% 20$ $\% 283 \% 29$.pdf\#page $=29$

Malinowski, B. (1978). Argonautas do Pacifico Ocidental: um relato do empreendimento e da aventura dos nativos nos arquipélagos da Nova Guiné Melanésia. São Paulo: Abril Cultural, 1978. (Coleção Os pensadores).

Malinowski, B. (1997). Um diário no sentido estrito do termo. Rio de Janeiro: Record.

Moreira, J. O., Oliveira, N. A., \& Costa, E. A. (2018). Psicanálise e pesquisa científica: o pesquisador na posição de analisante. Revista Tempo Psicanalítico, 50(2), 119-142. Recuperado a partir de http://pepsic.bvsalud.org/scielo. php?script=sci_arttext\&pid=S0101-48382018000200007

Nicolescu, B. (1999). O manifesto da transdisciplinaridade. L. P. Souza (Trad.). São Paulo: Triom. Recuperado a partir de http://www.ruipaz.pro.br/textos_ pos/manifesto.pdf 
Nicolescu, B. (2000). Um novo tipo de conhecimento: transdisciplinaridade. Educação e transdisciplinaridade, 1(2).

Piaget, J. (1983). A epistemologia genética. (2a ed.) N. C. Caixeriro, Z. Abujamra, \& C. E. Di Piero (Trads.). São Paulo: Abril Cultural, 1983. (Coleção Os Pensadores).

Silva, C. A. P. (2007). Resenha: O manifesto da transdisciplinaridade. Revista Famecos, 14(32), 137-139.

Sommerman, A. (2005). A inter e a transdisciplinaridade. In Seminário Internacional de Educação, Cachoeira do Sul (pp. 1-21).

Vasconcelos, E. M. (2009). Epistemologia, diálogos e saberes: estratégias para práticas interparadigmáticas em saúde mental. Cadernos Brasileiros de Saúde Mental, 1(1), 1-10. Recuperado a partir de http://stat.cbsm.incubadora.ufsc. $\mathrm{br} /$ index.php/cbsm/article/view/1006/1124

Waiselfisz, J. J. (2016). Mapa da violência 2016: homicídios por arma de fogo no Brasil. Brasília: FLACSO. Recuperado a partir de http://www.mapadaviolencia. org.br/pdf2016/Mapa2016_armas_web.pdf 